\title{
Seroprevalencia de anticuerpos contra la Brucella sp. en ganaderos del distrito San José de Lourdes, Cajamarca
}

\section{Seroprevalence of antibodies against Brucella sp. in cattle farmers in the San José de Lourdes district, Cajamarca}

\author{
Escolana Julcahuanca 1,a, Edit Pérez ${ }^{1, b}$, Cinthya Santa Cruz-López ${ }^{11, c}$, Marcela Saldaña ${ }^{1, d}$
}

\section{Filiación y grado académico \\ Universidad Nacional de Jaén, Facultad de Tecnología Médica, Cajamarca, Perú. \\ Bachiller de Tecnología Médica, Cajamarca, Perú. \\ b Bachiller en Tecnología Médica. \\ Doctora en Ciencias Biomédicas. \\ ${ }^{d}$ Maestra en Ciencias - Estadística aplicada. \\ (iD) ORCID iD de Escolana Julcahuanca https://orcid.org/0000-0001-6673-0514 \\ (iD) ORCID iD de Edit Pérez \\ https://orcid.org/0000-0002-7410-4190}

(i) ORCID iD de Cinthya Santa Cruz-López https://orcid.org/0000-0002-7352-058X

(iD) ORCID iD de Rosa Gálvez

https://orcid.org/0000-0001-9457-5697

Contribución de autoría

SJ y EP: concepción y diseño del estudio, búsqueda bibliográfica, recolección de los datos y participaron en la elaboración del manuscrito.

CSCL: ejecución de la investigación, revisó el borrador y la versión final del manuscrito. MS: análisis estadístico de los datos, elaboración y revisión del manuscrito.

Fuentes de financiamiento

El trabajo de investigación fue financiado con recursos propios.

Conflictos de interés

Los autores declaran no tener conflictos de interés.

Recibido: 22-01-2021

Arbitrado por pares

Aceptado: 15-04-2021

Citar como

Julcahuanca E, Pérez E, Santa Cruz-López $C$, Saldaña M. Seroprevalencia de anticuerpos contra la Brucella sp. en ganaderos del distrito San José de Lourdes, Cajamarca. Rev Peru Cienc Salud. 2021; 3(2): 82-8. doi: https://doi.org/10.37711/rpcs.2021.3.2.303

Correspondencia

Cinthya Yanina Santa Cruz-López

Dirección: Avenida Luis Gonzales 1342.

CP.: 14001

Celular: 945391136

Email: cisantacruzl@gmail.com

\section{RESUMEN}

Objetivo. Determinar la seroprevalencia de anticuerpos contra la Brucella sp. e identificar los factores predisponentes y la sintomatología asociada en los ganaderos del distrito San José de Lourdes (San Ignacio) en el departamento de Cajamarca, durante los meses de setiembre a diciembre del 2019. Métodos. El estudio fue de tipo observacional, transversal, prospectivo con un diseño exploratorio-descriptivo. Se realizó un muestreo probabilístico, donde se analizaron 147 sueros sanguíneos pertenecientes a ganaderos de ambos géneros. La seroprevalencia de anticuerpos se determinó mediante las pruebas Rosa de Bengala y antígeno de Huddleson y se aplicó una encuesta estructurada para identificar los factores predisponentes y la sintomatología asociada a la enfermedad. Resultados. Se encontró que, $17 \%$ de ganaderos seropositivos a Brucella $s p$. mantuvo contacto directo prolongado con el ganado bovino $(p<0,05)$. Además, el $23,8 \%$ de ganaderos presentó anticuerpos contra la Brucella sp, siendo principalmente mujeres (15,6 \%). Los ganaderos con anticuerpos contra la Brucella sp. consumían queso $(22,4 \%)$, leche $(19,7 \%)$ y sangre de animales sacrificados $(17 \%)(p>0,05)$. Los síntomas más recurrentes fueron el dolor de cabeza (19\%), fatiga (14,3\%), dolor articular $(13,6 \%)$, fiebre e insomnio (10,2 \%). Conclusiones. La seroprevalencia de anticuerpos contra la Brucella sp. es alta y está asociada al contacto directo prolongado con el ganado bovino y a síntomas como el dolor de cabeza y la fiebre, presentes en la población evaluada. Los resultados obtenidos permiten evidenciar la preocupante situación que viven los ganaderos de San José de Lourdes, además de la escasa cultura preventiva existente.

Palabras clave: Brucelosis; estudios seroepidemiológicos; pruebas serológicas; comunidad rural (Fuente: DeCS-BIREME).

\section{ABSTRACT}

Objective. To determine the seroprevalence of antibodies against Brucella sp. and to identify the predisposing factors and associated symptomatology in cattle farmers in the San José de Lourdes district (San Ignacio) in the department of Cajamarca, during the months of September to December 2019. Methods. The study was observational, cross-sectional, prospective with an exploratorydescriptive design. A probabilistic sampling was carried out, where 147 blood serums belonging to cattle of both genders were analyzed. The seroprevalence of antibodies was determined by Rose Bengal and Huddleson antigen tests and a structured survey was applied to identify predisposing factors and symptoms associated with the disease. Results. It was found that $17 \%$ of cattle farmers seropositive for Brucella $s p$. had prolonged direct contact with cattle ( $p<0.05$ ). In addition, $23.8 \%$ of farmers had antibodies against Brucella sp., being mainly women (15.6\%). Cattle farmers with antibodies against Brucella $s p$. consumed cheese $(22.4 \%)$, milk $(19.7 \%)$ and blood from slaughtered animals $(17 \%)(p>0.05)$. The most recurrent symptoms were headache $(19 \%)$, fatigue (14.3\%), joint pain (13.6\%), fever and insomnia (10.2\%). Conclusion. The seroprevalence of antibodies against Brucella sp. is high and is associated with prolonged direct contact with cattle and symptoms such as headache and fever, present in the population evaluated. The results obtained show the worrying situation of the cattle farmers of San José de Lourdes, in addition to the scarce preventive culture that exists.

Keywords: Brucellosis; seroepidemiological studies; serological tests; rural community (Source: MeSH - NLM). 


\section{INTRODUCCIÓN}

La brucelosis es una enfermedad causada por bacterias pertenecientes al género Brucella. Esta zoonosis origina significativas pérdidas económicas en la industria pecuaria. Asimismo, afecta la salud humana y genera elevados costos en la recuperación de las personas afectadas, lo que disminuye su productividad laboral a consecuencia de la incapacidad física temporal e incluso permanente que puede producir ${ }^{(1,2)}$.

Se estima que anualmente se diagnostican entre 5000000 y 12500000 nuevos casos de brucelosis en el hombre a nivel mundial, siendo más frecuentes en los países en vías de desarrollo ${ }^{(3)}$. La infección por Brucella sp. está relacionada con las condiciones socioeconómicas de cada país, debido a la utilización de un sistema tradicional para cuidado de los animales, sistemas sanitarios deficientes y desconocimiento sobre esta patología y sus formas de transmisión (2).

En el Perú, durante el año 2018, se registraron 63 casos positivos de brucelosis humana, de los cuales el $11,1 \%$ se reportaron en el departamento de Cajamarca ${ }^{(4)}$. Además, según el Ministerio de Agricultura y Riego, Cajamarca lidera la producción de carne bovina en el Perú y aproximadamente el $44 \%$ de los productores constituye una población en condición de pobreza y extrema pobreza ${ }^{(5)}$, incrementando la probabilidad de infección.

Las bacterias del género Brucella se transmiten al hombre principalmente por vía oral ${ }^{(6)}$, a través del consumo de alimentos como la leche o sus derivados (manteca, quesos) contaminados ${ }^{(1)}$. Los productos del aborto, sangre y vísceras también contienen una elevada carga bacteriana ${ }^{(7)}$. Sin embargo, existen otras vías de infección como la respiratoria (inhalación de polvo, pelo, excretas de animales infectados), cutánea y conjuntival (contacto directo con material contaminado). De modo que la asistencia en los partos, faena de animales y limpieza de los utensilios, máquinas y vertederos son las actividades más involucradas en la transmisión del patógeno ${ }^{(6,8)}$.

A pesar de ello, el número real de personas infectadas no se ve reflejado en las estadísticas oficiales, ya que la enfermedad muchas veces no es notificada oportunamente. Por lo que la verdadera incidencia podría ser hasta 25 veces mayor a la reportada ${ }^{(9)}$. Otro gran inconveniente en el diagnóstico ocurre porque los casos de brucelosis a menudo no son reconocidos clínicamente, ya que los síntomas suelen ser similares a los ocasionados por otras infecciones febriles ${ }^{(10)}$.
Las pruebas serológicas son muy útiles para el diagnóstico de la brucelosis humana ${ }^{(11)}$. Se caracterizan por tener bajo costo, ser fáciles de realizar y poseer alta sensibilidad y especificidad. Entre ellas, se encuentran las pruebas tamiz como Rosa de Bengala y Huddleson, siendo las más empleadas para detectar inmunoglobulinas M y G contra la Brucella sp. ${ }^{(8)}$.

Actualmente son escasos los estudios sobre la brucelosis en poblaciones que habitan en zonas rurales del Perú, pese al riesgo que representa la actividad económica que desempeñan. Cabe señalar que los pobladores de San José de Lourdes tienen como primordiales actividades económicas la agricultura y la ganadería, siendo la de ganado vacuno la principal explotación ganadera. En esta comunidad existen serias falencias a nivel sanitario, debido a la carencia de agua potable y por la existencia de una infraestructura hidráulica rústica. Sumado a ello, el difícil acceso de la comunidad a los sistemas de salud, al tratarse de zonas alejadas de las áreas urbanas, empeora la situación existente.

En consecuencia, resulta de gran importancia llevar a cabo estudios seroepidemiológicos que permitan un adecuado seguimiento de la enfermedad, evitando así futuras complicaciones en la salud de los ganaderos y de la población en general. Es así que la realidad antes descrita motivó el desarrollo de esta investigación, formulándose la siguiente interrogante: ¿cuál es la seroprevalencia de anticuerpos anti- Brucella sp. y su relación con los factores predisponentes y la sintomatología asociada en los ganaderos del distrito San José de Lourdes, departamento de Cajamarca durante el periodo de septiembre a diciembre del 2019?

Para dar respuesta a dicha problemática se plantearon como objetivos determinar la seroprevalencia de anticuerpos contra la Brucella sp. e identificar los factores predisponentes y la sintomatología asociada en los ganaderos del distrito San José de Lourdes, departamento de Cajamarca, durante el periodo de setiembre a diciembre del 2019.

\section{MÉTODOS}

\section{Tipo de estudio}

Estudio de tipo observacional, transversal y prospectivo con diseño no experimental de enfoque exploratorio descriptivo. Se trata de un diseño no experimental porque se basa fundamentalmente en la observación de los ganaderos en su ambiente natural y sin exponerlos a ningún estímulo; además, es exploratorio descriptivo 
porque busca describir la realidad respecto a la seroprevalencia de anticuerpos frente a Brucella sp y establecer su asociación con los factores predisponentes y la sintomatología relacionada a la brucelosis.

\section{Población y muestra}

La población de estudio estuvo conformada por ganaderos del distrito de San José de Lourdes, San Ignacio, Cajamarca (Latitud: -5.1025, Longitud: -78.9139), evaluados durante el periodo de septiembre a noviembre del 2019. Por su parte, la muestra fue de 147 ganaderos de ambos géneros, excluyendo a los ganaderos menores de edad y aquellos que no se encontraban en la comunidad al momento de recolectar los datos, de acuerdo a los criterios de inclusión y exclusión. El tamaño de la muestra se calculó empleando la fórmula estadística para poblaciones desconocidas, con un muestreo de tipo probabilístico, aleatorio simple.

\section{Instrumentos de recolección de datos}

Como técnica de recolección de datos se aplicó una encuesta dirigida a los ganaderos del distrito de San José de Lourdes (San Ignacio), con la finalidad de recopilar información acerca de la sintomatología, hábitos alimenticios, presencia de heridas o cortes realizados durante la faena, el uso de equipo de protección personal y contacto prolongado de los ganaderos con los animales. El instrumento de recolección de datos fue un cuestionario elaborado por Santa Cruz - López ${ }^{(12)}$. El método de estudio fue deductivo obtenido a partir de la observación, medición e interpretación minuciosa de la realidad descrita.

\section{Procedimientos de la recolección de datos}

Para determinar la seroprevalencia de anticuerpos contra la Brucella sp., se emplearon las pruebas del antígeno Rosa de Bengala y de Huddleson de tipo cualitativas. La sangre total de los ganaderos se recolectó de acuerdo al protocolo establecido por el Instituto Nacional de Salud del Perú ${ }^{(13)}$. Se utilizaron kits comerciales, siguiendo las indicaciones del fabricante ${ }^{(14,15)}$. La lectura se realizó con un microscopio óptico Boeco BM-120 a 400 aumentos.

\section{Análisis de datos}

Se realizó un análisis descriptivo de los datos con el paquete estadístico Minitab ${ }^{\circledR} 19$ para Windows ${ }^{\circledR}$ versión 8. Se emplearon frecuencias absolutas y relativas, y medias, para las variables cualitativas y cuantitativas, respectivamente. Además, se utilizó la prueba de chi cuadrado para establecer la asociación entre la seroprevalencia de anticuerpos contra la Brucella sp., los factores predisponentes y sintomatología presente en los ganaderos.

\section{Aspectos éticos}

El estudio fue revisado y aprobado por la Comisión Central de Investigación de la Universidad Nacional de Jaén. Además, la participación de los ganaderos fue voluntaria; previo a ello, se les explicó detalladamente en qué consistía el estudio y su participación en el mismo. Cabe señalar que las muestras sanguíneas y cuestionarios se identificaron mediante una codificación numérica seriada y la información obtenida solo se empleó con fines de investigación, de acuerdo a los establecido en la Declaración de Helsinki.

\section{RESULTADOS}

Se evaluaron 147 sueros sanguíneos de ganaderos de ambos géneros, pertenecientes al distrito de San José de Lourdes durante el año 2019. El 23,8 \% de ganaderos presentó anticuerpos contra la Brucella sp., de los cuales el 15,6 \% correspondió al género femenino y el 8,2 \% al género masculino. No se encontró relación significativa entre la seroprevalencia de anticuerpos y el género de los ganaderos (ver tabla 1).

Respecto a los factores predisponentes se evidenció que los ganaderos seropositivos a la Brucella sp. mantuvieron contacto directo con el ganado bovino $(17,0 \%)$ y porcino (10,6 \%). Por otro lado, se encontró que el $22,4 \%, 19,7 \%$ y $17,0 \%$ de los ganaderos que consumían frecuentemente queso, leche y sangre de animales sacrificados respectivamente, presentaron anticuerpos contra la Brucella sp. Asimismo, el 19,7\% de ganaderos manifestó tener heridas o haber sufrido cortes durante el sacrificio de los animales, encontrándose anticuerpos contra la Brucella sp. en el 6,8\% de estos ganaderos. Sumado a ello, el $100 \%$ de ganaderos no utilizaba equipos de protección personal (EPP), evidenciándose seropositividad frente a la Brucella sp. en el 23,8 \% de los casos. Sin embargo, solo se encontró

Tabla 1. Seroprevalencia anticuerpos contra la Brucella sp. según el género de los ganaderos

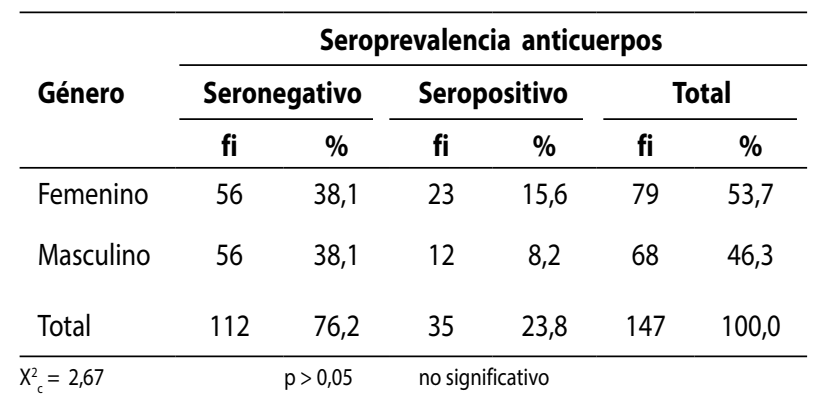


Tabla 2. Factores predisponentes de brucelosis en los ganaderos

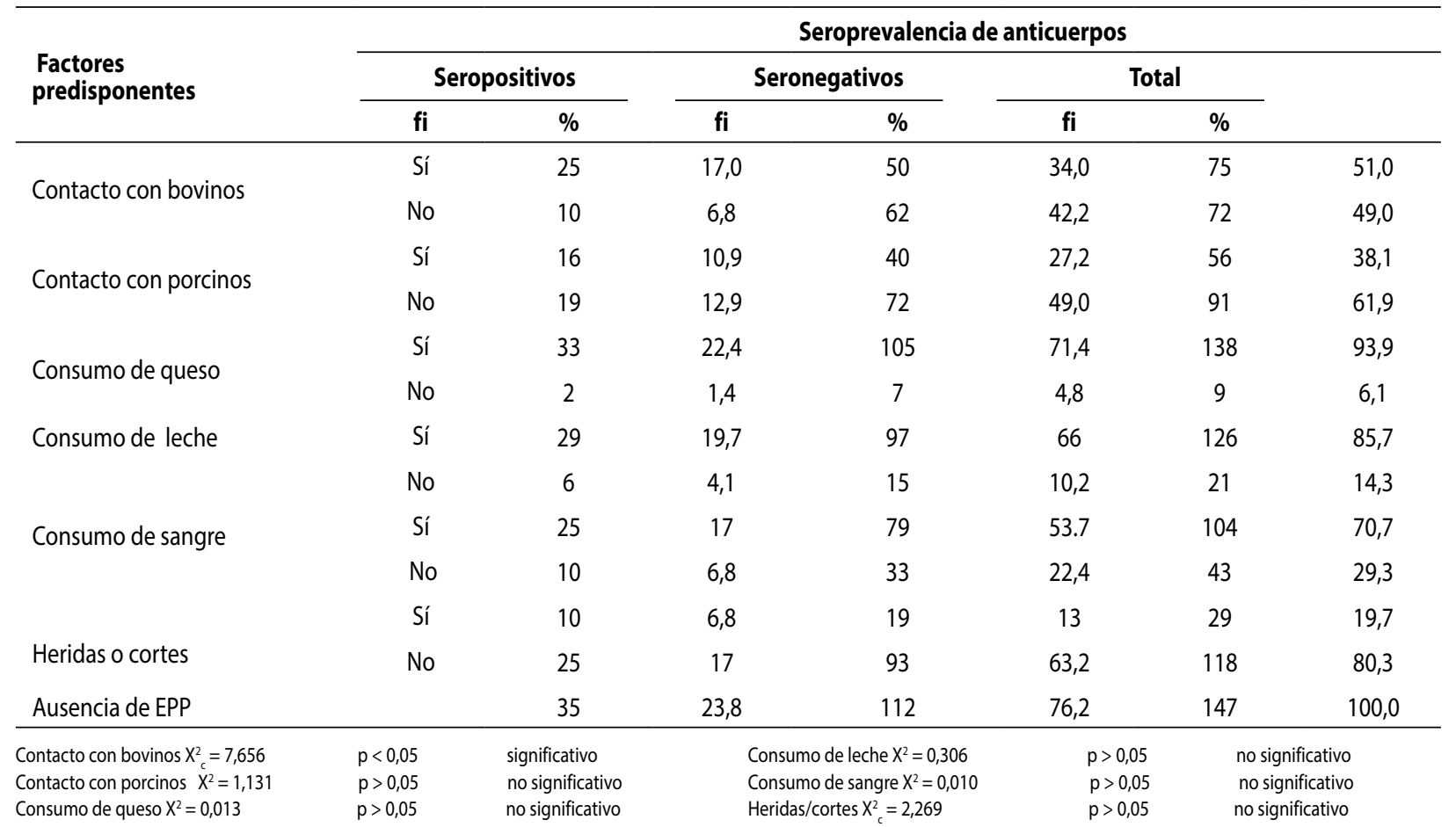

relación significativa entre la seropositividad de los ganaderos y su contacto directo permanente con el ganado bovino (ver tabla 2).

En la tabla 3 se reporta que los síntomas más frecuentes en los ganaderos con presencia de anticuerpos contra la Brucella sp. fueron el dolor de cabeza (19\%), fatiga $(14,3 \%)$, dolor articular (13,6\%), fiebre (10,2\%) e insomnio $(10,2 \%)$. Por consiguiente, se estableció la asociación significativa entre la seroprevalencia de anticuerpos y síntomas como el dolor de cabeza constante y la fiebre irregular $(\mathrm{p}<0,05)$.

Tabla 3. Manifestaciones clínicas de brucelosis asociadas a la seroprevalencia de anticuerpos contra la Brucella sp. en los ganaderos

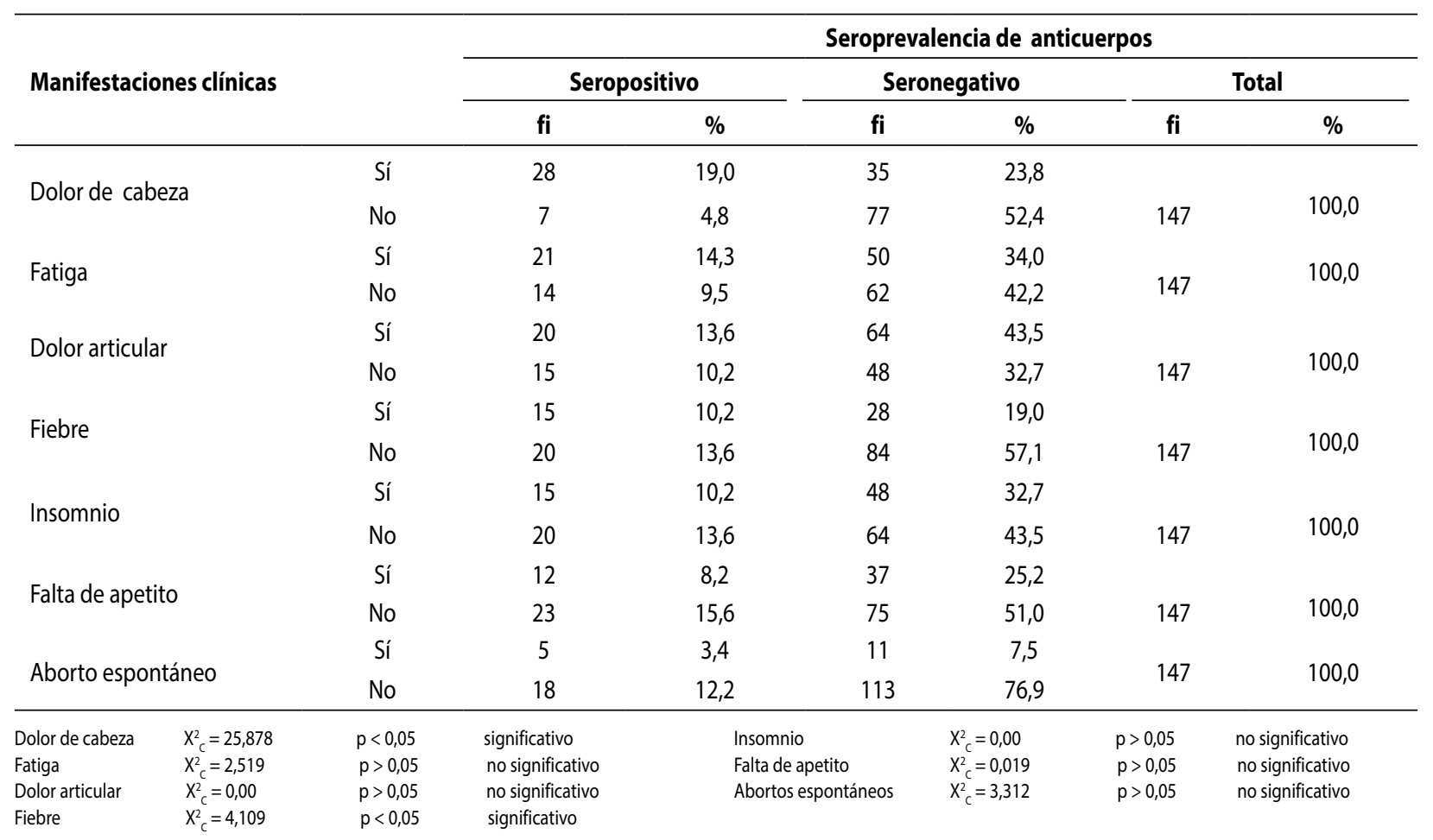




\section{DISCUSIÓN}

La presente investigación determinó la seroprevalencia de anticuerpos contra la Brucella $s p$., los factores predisponentes y la sintomatología presente en los ganaderos del distrito San José de Lourdes; una zona dedicada a la crianza de ganado vacuno, porcino y ovino, con condiciones que favorecen la infección con Brucella sp. En la tabla 1 se reportó una seroprevalencia del $23,8 \%$, siendo más frecuente en el género femenino $(15,6 \%)$. Este resultado superó al obtenido por Santa Cruz - López ${ }^{(12)}$, quien reportó una seroprevalencia del $10,7 \%$ en trabajadores de camales en Lambayeque, de los cuales el 9,2\% correspondió a trabajadores del género masculino, no existiendo relación significativa entre la enfermedad y el género, lo que coincide con lo reportado en este estudio $(p>0,05)$. Cabe señalar, que no se encontró evidencia de que el género sea un factor determinante para la brucelosis humana; es decir, tanto mujeres como varones pueden adquirir la enfermedad dependiendo de las actividades que realicen.

Las pruebas Rosa de Bengala y antígeno de Huddleson son muy empleadas para detectar la presencia de anticuerpos contra Brucella sp., debido a que son altamente sensibles y específicas, lo que brindó mayor validez al estudio. Según Obregón ${ }^{(16)}$, las pruebas de antígenos febriles (entre ellas el antígeno de Huddleson) tienen una sensibilidad y especificidad del $100 \%$ y $97,5 \%$, respectivamente, al emplear como Gold estándar (prueba de referencia) a la prueba de ELISA, evidenciando que esta prueba serológica contribuye significativamente a la vigilancia epidemiológica de la brucelosis. Mientras que, el antígeno Rosa de Bengala posee una sensibilidad y especificidad diagnóstica del $100 \%$ y $98 \%$, respectivamente ${ }^{(15)}$. Los estudios realizados por Cevallos et al. ${ }^{(17)}$ y Toledo et al. ${ }^{(18)}$, emplearon el antígeno Rosa de Bengala para el diagnóstico de brucelosis, resaltando su efectividad y la obtención de resultados confiables con mayor rapidez.

El contacto directo de individuos sanos con animales infectados es uno de los mecanismos que favorece la transmisión del patógeno. Diversas investigaciones evidenciaron la relación existente entre la seroprevalencia de brucelosis en animales con la infección en humanos, debido al contacto directo prolongado de los individuos con el ganado ${ }^{(11,19,20)}$. Al respecto, Méndez - Lozano et al. ${ }^{(21)}$ encontraron que la alta incidencia de brucelosis bovina incrementa en un $15 \%$ la brucelosis en humanos. En el presente estudio, el $17 \%$ y $10,9 \%$ de los ganaderos que mantuvieron contacto directo prolongado con el ganado bovino y porcino, respectivamente, presentaron anticuerpos contra la Brucella sp. (ver tabla 2), encontrándose relación significativa entre el contacto directo con el ganado bovino y seroprevalencia de anticuerpos frente Brucella sp. $(p<0,05)$.

El control de la brucelosis en animales presenta grandes limitantes debido a las costumbres y creencias de gran parte de los ganaderos, ya que realizan la crianza nómade y una inadecuada eliminación de los animales reactores positivos ${ }^{(22)}$. Los ganaderos de San José de Lourdes cruzan su ganado a través de la ciudad para dirigirlos a diferentes hatos a pastear, lo que también podría favorecer la diseminación del microorganismo. Sobre todo si se tiene en cuenta la resistencia que presenta esta bacteria, llegando a subsistir hasta 80 días en el estiércol o 110 días en la lana o pelo de los animales ${ }^{(6)}$. Por lo que constituye un riesgo significativo que puede afectar no solo a los ganaderos sino también a la población en general.

Respecto a la ingestión de alimentos contaminados, se reportó que el $22,4 \%, 19,7 \%$ y $17 \%$ de los ganaderos que consumían frecuentemente queso, leche y sangre de animales sacrificados, respectivamente, resultaron seropositivos a Brucella sp. (ver tabla 2). La prueba de chi cuadrado demostró que no existe asociación significativa entre la ingesta de alimentos contaminados y la seropositividad encontrada $(p<0,05)$. Estos resultados difieren de lo reportado por Obregón et al. ${ }^{(16)}$ y Oliveira et al. ${ }^{(23)}$ quienes notificaron la asociación entre la brucelosis humana y el consumo de leche cruda y productos lácteos artesanales. Otro estudio encontró como principal factor de riesgo al consumo de sangre de animales infectados ${ }^{(12)}$. Esta diferencia podría explicarse debido a que los ganaderos tienen como principal fuente de ingresos económicos los animales de crianza y algunos productos derivados de los mismos, siendo destinados principalmente a la venta y no a su consumo propio.

Los ganaderos evaluados no utilizaban equipos de protección durante la realización de sus faenas; por el contrario, solo empleaban prendas cotidianas, calzado precario, generalmente sandalias. Esta situación se debe al desconocimiento acerca de las medidas de protección necesarias, siendo de suma importancia concientizar a esta población sobre la importancia del uso de medidas de protección básicas para evitar la diseminación del microorganismo.

La brucelosis en el hombre presenta sintomatologías inespecíficas que van desde fiebre hasta complicaciones osteoarticulares, cardiovasculares, reproductivas y neurológicas. Sin embargo, en muchas ocasiones los pacientes son asintomáticos, sobre todo en las primeras 
etapas de la enfermedad ${ }^{(3)}$. Por lo que el diagnóstico clínico es difícil, pudiéndose confundir con otras enfermedades, por lo que es necesario su respaldo con exámenes de laboratorio ${ }^{(10,24)}$.

En la tabla 3 se presentaron los síntomas de los ganaderos y su relación con la seroprevalencia de la enfermedad. El síntoma más recurrente fue el dolor de cabeza (19\%), seguido de la fatiga (14,3\%), dolor articular $(13,6 \%)$, fiebre e insomnio (10,2 \%). Además, se estableció una relación estadísticamente significativa entre el dolor de cabeza y la fiebre con la presencia de anticuerpos $(p<0,05)$. Los resultados obtenidos coinciden con lo hallado por Santa Cruz - López ${ }^{(12)}$ quien reportó que el síntoma más frecuente de brucelosis en los trabajadores de camales fue el dolor de cabeza.

Cabe resaltar que, pese a la alta sensibilidad y especificidad de las técnicas empleadas, es necesario confirmar los casos reportados mediante cultivo microbiológico, lo que no se realizó en esta investigación. Tampoco se logró establecer asociación entre el uso de las medidas de protección y la infección por Brucella sp., debido a que ningún ganadero contaba con indumentaria adecuada, generando limitaciones en el estudio.

En conclusión, la seroprevalencia anticuerpos contra la Brucella sp. es de 23,8 \% y está asociada al contacto directo prolongado de los ganaderos con el ganado bovino, siendo el dolor de cabeza y la fiebre los síntomas asociados a la enfermedad. Combatir la brucelosis humana constituye un gran reto considerando las deficiencias del sistema sanitario y de salud existentes en el Perú. Por lo que es de suma importancia implementar sistemas de vigilancia epidemiológica que permitan el diagnóstico y control oportuno de brucelosis humana y animal en zonas rurales como el distrito de San José de Lourdes (San Ignacio), ya que debido a las actividades económicas realizadas por los pobladores y al desconocimiento, se encuentran en riesgo latente de contraer la enfermedad.

\section{REFERENCIAS}

1. Brucelosis [Internet] Ginebra: Organización Mundial de la Salud; 2020 [Consultado 2020 Dic 20] Disponible en: https://www.who.int/es/news-room/fact-sheets/detail/ brucellosis

2. Escobedo L, Falcón N. Características epidemiológicas y clínicas de infecciones por Brucella melitensis en pacientes del Hospital Nacional «Daniel A. Carrión», Callao, Perú (2007-2014). Rev. investig. vet. Perú [Internet]. 2018 Jul; 29 (3): 1018-24 [Consultado 2020 Dic 20]. Disponible en: http://www.scielo.org.pe/scielo.php?script=sci_arttext\&pid=S1609-91172018000300034\&lng=es. http:// dx.doi.org/10.15381/rivep.v29i3.14834
3. Hull NC, Schumaker BA. Comparisons of brucellosis between human and veterinary medicine. Infect. Ecol. Epidemiol. [Internet].2018 Jul; 8(1): 1-29 [Consultado 2020 Dic 20]. Disponible en: https://doi.org/10.1080/2000868 6.2018 .1500846

4. Sánchez JM, Gabriel AE. Anuario estadístico 2018. Lima: Ministerio de Salud, Instituto Nacional de Salud; 2018.

5. Dirección General de Políticas Agrarias. Diagnóstico de Crianzas Priorizadas para el Plan Ganadero 2017-2021. Lima: Ministerio de Agricultura y Riego; 2017.

6. Valle T, Lago Y, García I. Resultados de intervención educativa sobre brucelosis humana en zonas de riesgo de enfermar en Argelia. Rev. Ciencias Médicas de Pinar del Río [Internet]. 2018 Ago; 22(4): 153-63 [consultado 2020 Jun 20]. Disponible en: http://scielo.sld.cu/scielo.php?scrip$\mathrm{t}=\mathrm{sci}$ _arttext\&pid=S1561-31942018000400017\&lng=es

7. Dirección de Epidemiología. Enfermedades infecciosas brucelosis. Guía para el equipo de salud. Argentina: Ministerio de Salud de la Nación; 2013.

8. Rosales C, Puentes C, Arias O, Romero JJ. Aspectos epidemiológicos de la brucelosis en humanos en las Áreas Rectoras Aguas Zarcas y Los Chiles, Costa Rica, 20152017. Rev. Ciencias Veterinarias [Internet] 2020 Feb; 38 (1): 1-6 [Consultado 2020 Dic 20]. Disponible en: https:// doi.org/10.15359/rcv.38-1.1

9. Olivares R, Vidal P, Sotomayor C, Norambuena M, Luppi $M$, Silva $F$, et al. Brucelosis en Chile: descripción de una serie de 13 casos. Rev Chil Infectol. [Internet] 2017 Jun; 34: 243-47 [Consultado 2020 Dic 20]. Disponible en: http://dx.doi.org/10.4067/S0716-10182017000300006

10. Morales-García R, García-Méndez N, Regalado-Jacobo D, López-Merino A, Contreras-Rodríguez A. Seguimiento clínico, serológico y mediante la reacción de polimerasa en cadena de una familia con brucelosis. Rev. chil. Infectol. [Internet] 2014 Ago; 31(4): 42533 [Consultado 2020 Jun 20]. Disponible en: https:// scielo.conicyt.cl/scielo.php?script=sci_arttext\&pi$\mathrm{d}=$ S0716-10182014000400008\&lng=es

11. Pisani A, Vacarezza M, Tomasina F. Estudio de 14 casos de brucelosis en trabajadores de un frigorífico como enfermedad profesional. Uruguay 2009-2010. Rev Méd Urug [Internet]. 2017 Sep; 33(3): 93-8 [Consultado 2020 Jun 20]. Disponible en: http://dx.doi.org/10.29193/ rmu.33.3.1

12. Santa Cruz-López CY. Seroprevalencia de brucelosis en el personal que labora en camales del departamento de Lambayeque. Junio 2014 - febrero 2015 [Tesis de maestría en Ciencias] La libertad: Universidad Nacional de Trujillo; 2015.

13. Zurita S. Procedimientos de laboratorio: manual: laboratorios locales I Laboratorios locales II. Lima: Ministerio de Salud, Instituto Nacional de Salud; 2013.

14. Spinreact. Rose Bengal. Slide agglutination [Internet] España: [Consultado 2019 Sep 20] Disponible en: https:// www.spinreact.com/files/Inserts/Serologia/SGIS07_-Ref._1200901_Rosa_Bengala_04-2013.pdf

15. Wiener-lab. Antígenos Febriles [Internet] [Consultado 2019 Sep 20] Disponible en: https://www.wiener-lab. com.ar/VademecumDocumentos/Vademecum\%20espanol/antigenos_febriles_sp.pdf

16. Obregón A, Muñoz K, Echevarría E, Rodríguez Y, Rodríguez J, Valdés $Y$, et al. Evaluación del sistema serológico Febrille Antigen Brucella para la pesquisa de anticuer- 
pos contra brucelas, en Cuba. Rev Cubana Med Trop. [Internet]. 2015 Dic; 67(3): 1-9 [Consultado 2019 Sep 20]. Disponible en: http://scielo.sld.cu/scielo.php?script=sci_arttext\&pid=S037507602015000300001\&lng=es

17. Cevallos O, Carranza M, Saucedo S, Romero D, Ramos $L$, Reyes X. Diagnóstico serológico (Rosa de Bengala) y molecular (PCR) de brucelosis en humano. Rev. Ciencia y tecnología. [Internet]. 2010 Ene;1(3):27-32 [Consultado 2019 Sep]. Disponible en: https://uteq.edu.ec/revistacyt/publico/archivos/C1_5n12010.pdf

18. Toledo E, Delgado C, Suarez A, Noé M. Prevalencia de Brucelosis Caprina en tres distritos de la provincia de Cañete, Lima. Rev. Inv. Vet. Perú. [Internet] 2007 Jul;18(2): 136-40 [Consultado 2019 Sep 20]. Disponible en: http:// www.scielo.org.pe/scielo.php?script=sci_arttext\&pi$d=S 160991172007000200008 \& \operatorname{lng}=e s$

19. Zambrano MD, Pérez M, Rodríguez X. Brucelosis Bovina en la Provincia Manabí, Ecuador: Estudio de los Factores de Riesgo. Rev. investig. vet. Perú. [Internet] 2016 Sep; 27(3): 607-17 [Consultado 2020 Sep 20]. Disponible en: http://dx.doi.org/10.15381/rivep.v27i3.11995

20. Cervera-Hernández ME, Ordaz-Vázquez A, Torres-González $P$, Chávez-Mazari $B$, Soberanis-Ramos $O$, Sifuentes-Osornio J, et al. Seroprevalence of brucellosis among dairy farm workers in Mexico. Sal públ Méx. [Internet]
2016 May; 58 (3): 366-70 [Consultado 2020 Sep 20]. Disponible en: https://saludpublica.mx/index.php/spm/ article/view/7896

21. Méndez-Lozano M, Rodríguez E, Sánchez L. Brucelosis, una zoonosis presente en la población: estudio de series de tiempo en México. Rev Sal Pub México [Internet]. 2015 Dic; 57(6): 519-27 [Consultado 2020 Sep 20]. Disponible en: http://www.scielo.org.mx/scielo.php?scrip$\mathrm{t}=\mathrm{sci}$ _arttext\&pid=S003636342015000600010\&lng=es

22. Navarro A, Bustamante J, Guillen A. Estrategias de prevención y control de la brucelosis humana en el Perú. Rev Perú Med Exp Salud Publica. [Internet]. 2005 Abr; 22: 87 [Consultado 2020 Nov 20]. Disponible en: http:// www.scielo.org.pe/scielo.php?script=sci_arttext\&pi$\mathrm{d}=\mathrm{S} 172646342005000200001$ \&lng=es

23. Oliveira C, Almeida J, Feitosa A, Firmino S, Rocha M, Da Silva-Júnior F. Prevalencia de la Brucella spp en humanos. Rev. Lat.-Am. Enferm. [Internet] 2015 Oct; 23(5): 919-26 [Consultado 2020 Nov 20]. Disponible en: https://doi. org/10.1590/0104-1169.0350.2632

24. Doganay M, Aygen B. Human brucellosis: an overview. International Journal of Infectious Diseases [Internet] 2003; 7(3): 173-82 [Consultado 2020 Nov 20] Disponible en: https://www.ijidonline.com/article/S1201-9712(03)90049-X/ pdf. https://doi.org/10.1016/S1201-9712(03)90049-X 